\title{
An International Agreement on Pandemic Prevention and Preparedness
}

\author{
Lawrence O. Gostin \\ Georgetown University - Law Center - O'Neill Institute for National and Global Health Law, \\ gostin@law.georgetown.edu \\ Sam F. Halabi \\ O'Neill Institute for National and Global Health Law, Georgetown University, sfh@georgetown.edu \\ Kevin A. Klock \\ Foundation for the National Institutes of Health
}

This paper can be downloaded free of charge from:

https://scholarship.law.georgetown.edu/facpub/2409

https://ssrn.com/abstract=3930309

The Journal of the American Medical Association, published online September 15, 2021, at 1-2.

This open-access article is brought to you by the Georgetown Law Library. Posted with permission of the author. Follow this and additional works at: https://scholarship.law.georgetown.edu/facpub

Part of the Health Law and Policy Commons 


\section{An International Agreement on Pandemic Prevention and Preparedness}

Lawrence O. Gostin, JD (corresponding author)

O'Neill Institute for National and Global Health Law

Georgetown University Law Center

600 New Jersey Avenue, NW

Washington, DC 20001, USA

gostin@law.georgetown.edu

Sam Halabi, JD, MPhil

O'Neill Institute for National Global Health Law

Georgetown University Law Center

On March 30th, 2021, the heads of state of 25 nations, joined by the World Health Organization (WHO), called for an international treaty on pandemic prevention and preparedness - the highest level of political action to avert and respond to future health crises. ${ }^{1}$ In an historic action, 194 countries passed a World Health Assembly (WHA) resolution to host a special session devoted solely to an international pandemic agreement, now scheduled for November $29^{\text {th }}{ }^{2}$ The WHA special session will be preceded by the United Nations General Assembly and the G-20 group of nations. WHO Director-General Tedros Ghebreyesus referred to these 3 events as critical in shaping global health security. ${ }^{3}$ Georgetown University's O'Neill Institute, partnering with the Foundation of the National Institutes of Health, is hosting international expert consultations to support WHO and its member states in the development of an international agreement on pandemic prevention and preparedness.

\section{Gaps in Global Governance}

The response to the unfolding COVID-19 pandemic has exposed severe limitations in both the International Health Regulations (IHR) and WHO's institutional capacities. The IHR, fundamentally revised in the aftermath of SARS-1, exposed gaps in global governance, including: (1) China's failure to notify WHO promptly of a widely circulating novel coronavirus in Wuhan and WHO's inability to independently verify state reports; (2) weak WHO compliance mechanisms to enforce IHR obligations and its own recommendations; (3) WHO's lack of power to monitor, investigate, and remediate harmful actions; (4) insufficient transparency and international exchange of scientific data; and (5) lack of global cooperation, especially in the equitable allocation of vaccines and other medical resources.

Even the most basic investigations, such as to ascertain SARS-CoV-2's origins, have thus far proved unsuccessful. Perhaps most important, two-thirds of countries do not have IHR core health systems capacities to detect and alert the global community about novel outbreaks, including communications, surveillance, and response.

\section{Legal Options for WHO and the United Nations}


While WHO and the IHR have been the focus of global attention, the United Nations has extensive power and experience in negotiating large-scale treaties such as the Framework Convention on Climate Change and the Convention on the Rights of Persons with Disabilities. The Global Preparedness Monitoring Board, convened by WHO and the World Bank, recommended a pandemic treaty under UN auspices. The UN has comparative advantages, including its multisectoral approach (climate, food, animal health), enhanced compliance capabilities, and the ability to raise pandemic preparedness to the highest levels of government. The UN also has wide experience in financing, supply chain management, and humanitarian response, all vital during a global health emergency.

The WHA envisaged a WHO instrument, as the leading UN specialized agency for health. WHO has broad constitutional authority to adopt regulations under Article 21 , such as the IHR. The Assembly could renegotiate those regulations, but the IHR has limited scope, and weak compliance. WHO can adopt also a convention or agreement under Article 19, which it has done only once, for the Framework Convention on Tobacco Control. A Framework Convention grants countries wide flexibility, enabling consensus on broad principles of global health security that can be strengthened over time with detailed protocols.

The United States has expressed interest in heightened transparency and accountability through a non-binding agreement as opposed to a new treaty. ${ }^{4}$ Article 23 empowers the WHA to adopt non-binding recommendations, which has created important global health norms, such as on the marketing of infant formula and the international recruitment of healthcare workers. The Organization has also negotiated the Pandemic Influenza Preparedness (PIP) Framework to facilitate equitable sharing of pathogens for novel influenza viruses. Under the PIP Framework, pharmaceutical companies and laboratories committed to real-time production of vaccines, or other contributions, to benefit poorer countries.

The United Nations system, including WHO, has broad authority to create powerful norms and compliance mechanisms to strengthen global health security, with choices ranging from revising the IHR and adopting a framework convention through to non-binding recommendations or instruments.

\section{Core Content for an International Instrument}

The potential breadth of pandemic prevention and preparedness is wide-ranging and negotiations among 194 WHO member states will be challenging. Responding to vast gaps in the COVID-19 pandemic response should include: ${ }^{5}$

Zoonotic Spillovers. The IHR focuses on response to novel outbreaks after they occur. A new instrument could focus also on prevention of naturally occurring zoonoses, responsible for an estimated 75 percent of new human diseases. Separating animal and human populations could prevent spillovers, such as through land management, reforestation, and the effective regulation of wild animal trade and markets. Researchers have already generated predictive models to identify where spillovers are likely. ${ }^{6}$ 
Biosecurity and Biosafety. While SARS-CoV-2 most likely occurred in nature, a laboratory leak at the Wuhan Institute of Virology is an alternative theory of the virus' origin. Rigorous regulation and inspection of laboratory safety, as well as gain-of-function research, could help prevent unintentional or deliberate release of novel pathogens. WHO has issued international guidance on biosafety that could be incorporated into a new agreement. ${ }^{7}$

Monitoring, Inspection and Compliance. Responding to weak IHR compliance and accountability mechanisms, a new international instrument should enhance WHO or UN authority and legitimacy to independently verify state reports, publish crucial outbreak data without state confirmation, investigate novel outbreaks, and institute remedial actions. Norms are only effective if they are implemented at the national and local level in a fully transparent and cooperative manner.

Research, Scientific Sharing and Transparency. Undoubtedly the pandemic's greatest success came with the rapid development of vaccines and therapeutics, including with innovative mRNA technologies. Yet, open access and sharing of real-time virus samples, genomic sequencing, clinical trial and other research data and tools were often lacking. A new legal instrument could channel significant research funding, while promoting open access, full transparency, public/private partnerships, and scientific cooperation.

Health Systems. Underpinning rapid and effective response to novel pathogens requires robust health system capacities, including human resources, surveillance, laboratories, and risk communication. Capacities for testing, contact tracing, and vaccinating populations are crucial. Clinics, community health workers, and hospitals are needed to care for and treat patients during spikes in serious disease, as well as meeting everyday needs such as childhood vaccinations, maternal care, and caring for patients with non-communicable diseases. An international agreement could address states' failures to comply with Article 44 of the IHR, which calls for international technical and financial assistance to strengthen national public health capacities. ${ }^{8}$

Domestic and International Equity. The COVID-19 pandemic revealed cavernous divides based on race, gender, disability, and socioeconomic status both in the disproportionate numbers of hospitalizations and deaths and in access essential medical countermeasures. Highincome countries dominated the global market in diagnostics, PPE, therapeutics and especially vaccines. WHO and partners designed the ACT-Accelerator to accelerate development, production, and equitable access to COVID-19 tests, treatments, and vaccines. Yet, as of September $3^{\text {rd }}$, COVAX (the ACT-Accelerator's vaccine pillar) had shipped only 236 million COVID-19 vaccines to 139 countries, leaving most lower-income health workers and vulnerable populations unprotected. ${ }^{9}$ Any new international agreement must plan for adequate supplies of medical resources and equitable allocation among countries. This could include securing supply chains, intellectual property waivers, knowledge-sharing and technology transfers, along with ample donation of supplies. ${ }^{10}$ 
The compound health, economic, social, and humanitarian crises caused by the novel coronavirus, SARS-CoV-2, provides a compelling justification for a new international agreement on pandemic prevention and preparedness. It is possible to significantly reduce the likelihood of future novel outbreaks and to fortify the response through international cooperation, an empowered and well-funded WHO, and strong domestic health systems.

Disclosures: The authors, along with Kevin A. Klock of the Foundation for the National Institutes of Health (FNIH), are leading the $\mathrm{O}^{\prime}$ Neill Institute/FNIH project on an international instrument for pandemic prevention and preparedness. The Foundation provided funding for the project. Prof. Gostin is Director of the WHO Collaborating Center on National and Global Health Law.

\footnotetext{
${ }^{1}$ World Health Organization, Global Leaders Unite in Urgent Call for International Pandemic Treaty, Mar. 30, 2021 https://www.who.int/news/item/30-03-2021-global-leaders-unite-in-urgent-call-for-international-pandemictreaty.

${ }^{2}$ Resolution WHA74.16. Special session of the World Health Assembly to consider developing a WHO convention, agreement or other international instrument on pandemic preparedness and response. In: Seventy-fourth World Health Assembly, Geneva, 27-29 May 2021.

${ }^{3}$ Statement of Tedros Adhanom Ghebreyesus, August 25, 2021, https://twitter.com/GHS/status/1430670071299330048.

${ }^{4}$ Blinken AJ, Becerra X. Strengthening Global Health Security and Reforming the International Health Regulations: Making the World Safer From Future Pandemics. JAMA. Published online August 31, 2021. doi:10.1001/jama.2021.15611

${ }^{5}$ Gostin LO. Global Health Security: A Blueprint for the Future. Cambridge: Harvard University Press; 2021.

${ }^{6}$ Rourke M, Halabi S, Burci GL, Katz R. The Nagoya Protocol and the Legal Structure of Global Biogenomic Research. Yale Journal of International Law. 2020; 45(1); 145.

${ }^{7}$ World Health Organization. Laboratory Biosafety Manual 4th ed. 2020.

${ }^{8}$ Cinà MM, Hoffman SJ, Burci GL, et al. The Stellenbosch consensus on the international legal obligation to collaborate and assist in addressing pandemics. International Organizations Law Review 2020, doi: https://doi.org/10.1163/15723747-2020024.

${ }^{9}$ Gavi, COVAX Vaccine Rollout, https://www.gavi.org/covax-vaccine-roll-out

${ }^{10}$ Kavanagh MM, Gostin LO, Sunder M. Sharing Technology and Vaccine Doses to Address Global Vaccine Inequity and End the COVID-19 Pandemic. JAMA. 2021;326(3):219-220. doi:10.1001/jama.2021.10823.
} 